\title{
Modelling relationships between students' academic achievement and community of inquiry in an online learning environment for a blended course
}

\author{
Jeanette Lyn Fung Choy and Choon Lang Quek \\ Nanyang Technological University, Singapore
}

\begin{abstract}
With the advancement in technology, learners are spending a substantial amount of time on online learning. Guided by the community of inquiry (CoI) framework (Garrison, Anderson, \& Archer, 1999), this study examined the relationships among students' perceived teaching element, social element, cognitive element, satisfaction, continuous academic-related online performance, and academic achievement. A revised form of the CoI survey instrument was administered to 167 polytechnic students (aged between 17 and 24) enrolled in a nutrition course in a polytechnic in Singapore. Results from path analysis confirmed the hypothesised relationships among the three elements of the CoI framework (i.e., social, teaching, and cognitive) and students' learningrelated outcomes (i.e., satisfaction, continuous academic-related online performance, and academic achievement). However, only the cognitive element had a direct relationship with continuous academic-related online performance and satisfaction. In addition, the continuous academic-related online performance mediated the relationships between the cognitive element and academic achievement. Generally, the hypothesized model was able to explain $46 \%$ of the variance in students' online course satisfaction and $62 \%$ of the variance in students' academic achievements.
\end{abstract}

\section{Introduction}

Online learning has risen to prominence as a common teaching and learning mode in higher education institutions. In addition to or as a replacement for going to class to acquire content knowledge from the teacher directly, students can receive lesson materials and participate in learning activities with their peers at their own convenience. Yet, in this effort to supplement or replace face-to-face classroom learning, many online learning environments often replicate the ineffective methods that limit learning in face-to-face classrooms (Turoff, 1995).

The most valuable learning activity is argued to be one that provides students with the opportunity to "work and interact together and to build and become part of a community of scholars and practitioners" (Jonassen, Davidson, Collins, Campbell, \& Haag, 1995, p. 7). This idea that students should be actively involved in the learning process relates closely to that of constructivist principles where teachers create a learner-centred, collaborative environments and that students are supported to be active participants in their learning. Burge and Roberts (1993) contended that technology used in online education should also provide students with these valuable learning experiences. With advancements in technology, students can be provided with opportunities to experience the social and cognitive processes of knowledge construction (Quek, 2007). Thus, it is possible for increased interactions and collaboration among students and with the teacher in an online learning environment to occur. This had prompted educators to re-design instructional approaches and resources for the globally and dynamically emerging constructivist environment to meet the diverse learning needs of students (Heinich, Molenda, Russel, \& Smaldino, 2002). One pedagogical innovation that has received increased adoption in higher education is a combination of the traditional classroom approach with online learning, termed as blended learning (Garrison \& Kanuka, 2004). Blended learning was reported to be much favoured over fully online learning (Cheung \& Hew, 2011). For instance, in the blended learning approach, students have more control over their learning through asynchronous online learning, and at the same time, the face-to-face instruction enables them to maintain quality faculty-student interaction in the classroom (Chung \& Davis, 1995; Dukes, Waring, \& Koorland, 2006; Martyn, 2003). The advantages of a blended learning approach were also reported in a meta-analysis conducted by Means, Toyama, Murphy, Bakia, and Jones (2009). From their review of 56 studies that compared online and traditional classroom learning contexts, learners in the online context 
were found to have performed significantly better than their peers in the traditional classrooms. The authors made further observations that a combination of online and face-to-face learning resulted in higher gain than a context where learning is done fully online. Blended learning offers opportunities for learners to connect flexibly with a community of learners anytime and anywhere. In addition, the face-to-face contact was retained as part of the course experience. Connections between learners are an essential element for quality education as studies have shown that this can help to enhance students' satisfaction and learning (Rovai, 2002; Rovai \& Jordan, 2004; Sergiovanni, 1994; Shea, Li, \& Pickett, 2006).

Yet, simply combining aspects of online and face-to-face instructional techniques does not guarantee a quality learning outcome. Typically, an online learning environment incorporates both asynchronous and synchronous communications as well as various instructional approaches to provide a more complex and dynamic learning space for learners. While online learning offers extra dimensions to classroom learning in terms of both space and time flexibility, inherent problems encountered in online learning should be addressed carefully. Issues such as feeling isolated from peers (Wanstreet, 2006), lack of clear instruction and prompt feedback from the instructor (Hara \& Kling, 2001), as well as superficial interaction with online content (Dunlap, Sobel, \& Sands, 2007) often results in students reporting unsatisfactory educational experiences, which may lead to unsuccessful educational outcomes. In an online learning environment where learners and instructor are separated by space and time, creating proper structure (i.e., design) and developing meaningful interaction (i.e., online dialogue) are hailed as the fundamental element in generating a strong sense of learning community (Garrison, Anderson, \& Archer, 2003; Picciano, 2002).

With the widespread adoption of online learning to replace classroom learning, it is essential to understand how the mechanism of online interactions supports a meaningful online educational learning. The community of inquiry (CoI) framework to guide the research and practice of online learning has received much attention in the literature in recent years. According to Garrison et a. (1999), the CoI model states that a meaningful online educational learning is experienced through the development of three interlocking components. The components consist of cognitive presence (e.g., reflection, deep learning processes), social presence (e.g., interaction, collaboration), and teaching presence (e.g., course structure, content knowledge). The purpose of this study was to explore post-secondary students' online learning experience in an elective course that was delivered in a blended learning approach through elements within the CoI framework. This study was guided by two research questions:

- What is the level of the CoI components of social, teaching, and cognitive presence in the online learning environment of the blended course?

- What are the relationships among the social element, teaching element, cognitive element, online satisfaction, and academic achievement?

\section{Theoretical background}

When traversing across online and face-to-face contexts in a blended environment, it is important for students to receive adequate and responsive support from instructors and peers to obtain a quality learning outcome. The $\mathrm{CoI}$ framework has been used extensively to guide research designed to inform the quality of online education. In this framework, Garrison et al. (1999) suggested that meaningful online learning experience can be examined through three interlocking components: social presence, cognitive presence, and teaching presence.

\section{Social presence}

Social presence refers to the extent to which a person feels connected with others, both socially and emotionally. The dimensions of social presence are open communication, group cohesion, and affective expression (Garrison \& Arbaugh, 2007). In online learning, where learners are isolated from their peers and teachers, having a high degree of social presence enables learners to feel the existence of oneself and others, which leads to having feelings of connectedness and belonging (Gunawardena, 1995; Gunawardena \& Zittle, 1997; So \& Kim, 2005). 
Some studies have found a strong relationship between social presence and course satisfaction. For instance, Gunawardena and Zittle (1997) performed a stepwise regression analysis on data collected from 50 graduate students and found that social presence alone contributed about $60 \%$ of the variance in predicting satisfaction. In another study where Hostetter and Busch (2006) conducted an ordinary least squares regression test with data collected from 112 undergraduate online students, social presence accounted for $40 \%$ of the variance in the students' satisfaction scores. Yet, other studies have not reported a significant relationship between social presence and course satisfaction. For instance, through multiple regression analysis on data collected from 48 graduate students who attended a blended-format course in health education, So and Brush (2008) found no significant relationship between social presence and course satisfaction. As compared to the previous context (i.e., Gunawardena \& Zittle, 1997; Richardson \& Swan, 2003) where participation in online interaction was mandated by the course, the authors highlighted that students' involvement in online interaction in the health education course was voluntary. Given that the course was delivered through a blended learning approach where students had opportunities for face-to-face interaction, So and Brush (2008) suggested that opportunity for students to develop a sense of social presence might be limited as they might not see the need to connect with their peers through online communication technology. Similarly, in another study based on data collected from 81 students enrolled in an online university in Korea, although the level of interactivity was found to be a significant predictor of social presence, Kim, Kwon, and Cho (2011) found that social presence was not a significant predictor of learning satisfaction. Different from the course that was delivered in a blended format in the So and Brush (2008) study, the course under study in the Kim et al. (2011) case was delivered fully online. Through deeper investigation into the developmental nature of social presence, the authors suggest that social presence needs to reach a certain point, termed as the "critical mass", in order to have significant influence on learning satisfaction. Thus, it is necessary to introduce the importance of social presence in the early stage of the course. This is to accumulate students' social presence to reach the critical mass so that it can have a direct effect on their learning experience.

Findings from research that examined the relationship between social presence and learning achievement are inconclusive. For example, some studies found significant relationship between social presence and students' self-reported measures of learning achievement (Arbaugh, 2008; Richardson \& Swan, 2003). However, Picciano (2002) found that while social presence has a significant effect on students' performance on a written assignment, no significant effect was reported on students' performance on the examination. Unlike the studies reported earlier (i.e., Arbaugh, 2008; Richardson \& Swan, 2003), Picciano (2002) used actual measures of students' learning achievement to determine students' learning achievement. These actual measures included the examination paper that was designed to assess knowledge of the subject matter and the written assignment that was designed to examine students' ability to apply their knowledge through responding to a case study. It was observed that these studies utilised data analysis methods that did not account for the variance shared by other predictor variables (e.g., correlational analysis and standardised regression analysis). Even so, using ordinary least squares regression test on data obtained from 112 undergraduate students, Hostetter and Busch (2006) found no significant relationship between social presence and students' scores on their individual papers. Two explanations suggested by the authors are that the students generally earned high grades on their papers and there was not enough variation in their grades to adequately examine their relationship with social presence.

Overall, it appears that for the perceived level of social presence to have significant influence on students' satisfaction, instructions on how students should participate in online interactions as well as the nature of online interactions needs to be taken into consideration. Further exploration into the relationship between social presence and students' learning achievement using actual measures of students' learning achievement is needed.

\section{Cognitive presence}

Cognitive presence refers to learners' abilities to construct and confirm meaning through sustained reflection and discourse as they engage in the course content (Garrison \& Arbaugh, 2007). It is built upon Dewey’s (1933) view of practical inquiry. For students to experience cognitive presence to the highest level, they need to go through four phases, namely (a) a triggering event, (b) exploration, (c) integration and (d) resolution. The role of the instructor, discourse among learners, structure of the online learning environment and course design can significantly increase the extent that learners engage in the course content (Garrison \& Cleveland-Innes, 2005; 
Shea \& Bidjerano, 2009). Contrary to what had been reported in previous research related to lower levels of cognitive presence generally perceived by online students (Garrison et al., 1999, 2001; Garrison \& ClevelandInnes, 2005), Shea and Bidjerano (2005) contended that it is possible for students enrolled in a typical online learning environment to achieve higher levels of cognitive presence. The authors posited that in measuring cognitive presence, researchers should look at various course artefacts for evidence of higher cognitive presence and not be limited to student online communicative processes, such as threaded discussion and chats, as adopted by previous researchers.

There is limited empirical research on how cognitive presence by itself influences satisfaction and academic achievement. Nevertheless, Akyol and Garrison (2011) found a strong correlation among students' perceived level of cognitive presence, perceived learning and satisfaction in a blended course.

\section{Teaching presence}

Teaching presence refers to the designing, facilitating, and directing of social and cognitive processes throughout the learning experiences so as to obtain educational learning outcomes. Garrison and ClevelandInnes (2005) contended that interactions alone are not sufficient to ensure effective online learning. Teaching presence begins prior, during and at the end of the course. Taking the role of an instructional designer, the teacher makes preparation for the online lesson and orchestrates both the social and content-related interactions among participants.. Teaching presence is commonly reported as having three dimensions: (a) the design and organisation of the lesson, (b) the facilitation of productive discourse and (c) the provision of directed instruction on relevant course issues (Anderson, Liam, Garrison, \& Archer, 2001; Arbaugh \& Hwang, 2006). The central role of teaching presence in an online learning environment was examined in various studies (Ke, 2010; Shea et al., 2006; Shea, Li, Swan, \& Pickett, 2005), where it was reported to be a significant predictor for students' sense of a learning community (social presence) and the development of students' enquiry on the course content (cognitive presence).

Previous research results have consistently indicated that all the dimensions of teaching presence strongly correlate with students' satisfaction and perceived learning (Babb, Stewart, \& Johnson, 2010; Garrison \& Cleveland-Innes 2005; Picciano, 2002; Shea, Fredericksen, Pickett, \& Pelz, 2003).

Most of the studies reported here did not account for the variance shared by other predictor variables in the CoI framework when examining the dynamic relationships with students' related outcomes in an online learning environment. Garrison and Arbaugh (2007) argued for the need to consider the three interlocking components of the CoI framework to understand the online learning environment as experienced by students. In addition, the appropriateness of using self-reported measures on students' learning achievement and examination scores as measures of students' performance as a result of online learning needs to be examined.

\section{Model of relationships among social, teaching and cognitive presence in predicting course satisfaction and academic performance}

The relationships among these three presences have been analysed and confirmed in various studies (Arbaugh et al., 2008; Garrison, Cleveland-Innes, \& Fung, 2010; Joo, Lim, \& Kim, 2011; Shea \& Bidjerano, 2009). Based on the theoretical model of the CoI framework, student perceptions of teaching presence have a direct impact on students' perceived levels of social presence and cognitive presence. In addition, social presence functions as a mediator for teaching presence in predicting cognitive presence. However, few studies have examined how these elements come together to predict satisfaction and academic achievement.

Though limited, some studies provide insights towards understanding these relationships. For instance, Arbaugh (2008) conducted hierarchical regression analysis on data collected from 656 out of 1200 students that attended online courses in a Master of Business Administration program. Based on the results, the author reported that the framework accounted for $54 \%$ of the variance in student perceived learning and $22 \%$ of the variance in delivery medium satisfaction. While all three presences were reported to be significant predictors of perceived student learning, only teaching presence and social presence were significant predictors of delivery medium 
satisfaction. Conversely, in another large-scale study based on data collected from 709 out of 1200 students enrolled in an introductory computer skill course in an online university in Korea, Joo et al. (2011) observed that only teaching presence and cognitive presence were significant predictors of satisfaction. In a more recent research based on data collected from 335 out of 2708 undergraduate students, Enightoola, Fraser, and Brunton (2014) reported that the framework accounted for $29 \%$ of the variance in perceived learning and $36 \%$ of the variance in satisfaction. From examining the correlation matrix, the authors reported that certain dimensions of each presence in the CoI framework were positively correlated with satisfaction and learning. For instance, the dimension of direct instruction within teaching presence and the dimension of group cohesion within social presence were positively correlated with learning. The dimensions that were found to be positively correlated with satisfaction were reported to be open communication within social presence, exploration within cognitive presence, and resolution within cognitive presence. Yet, based on data gathered from 15 out of 16 students who attended a blended course, Akyol and Garrison (2011) reported that all three presences were significantly correlated with satisfaction. However, only teaching presence and cognitive presence were significantly correlated with perceived learning.

In summary, this literature review suggests that the research context, such as mode of delivery and nature of online interactions, might play a substantial role in influencing course satisfaction. In terms of predicting learning achievement, factors such as examining various course artefacts and how learning is being measured (i.e., between actual achievement and performance measures versus self-judgement of learning) need to be reviewed carefully. Particularly if learning materials are presented online (Ackerman \& Goldsmith, 2011; Ackerman \& Lauterman, 2012), the aspect of how learning is being measured may result in different outcomes (Koriat \& Bjork, 2005; Rhodes \& Castel, 2008). One of the difficulties in establishing the predictive ability of the CoI framework with regard to students' learning is that these studies measure learning in very different ways. Most studies reported here rely on self-reported measures of perceived learning while some rely on measures of learning achievements. Kruger and Dunning (1999) cautioned the use of perceived learning for self-assessment of knowledge to be carefully interpreted as learners may overestimate their capabilities. For the purpose of this study, we therefore decided to examine students' learning achievements in a blended course with their actual achievement and performance.

Students' learning achievement refers to an assessment of "what is learned" (Glaser \& Nitko, 1971). Glaser and Nitko elaborated that "what" includes both content and process and "learned" as the degree to which an individual learner is able to meet the specified performance criteria. In measuring the level of content attainment, one of the measures widely adopted by researchers is the use of standardised test scores (e.g., scores obtained from a paper and pen test or high-stakes examination). Yet, relating success from standardised tests with students' online learning experiences in a blended learning approach entails challenges. Assessment methods, such as examination or test, mostly measure students' knowledge retention (Choppin, 1990) and is done mainly for accountability reasons (Association of American Colleges and Universities, 2008). Gaytan and McEwen (2007) and Reeves (2000) argued that assessment practices for online learning should go beyond the traditional approach of assessing mainly content knowledge. In addition, rather than reviewing what students have learnt episodically, Gaytan and McEween (2007) reasoned that assessment measures should consider students' online performance over time. Particularly for a blended approach, where face-to-face classroom experience is part of the overall learning experience, it might not be adequate to solely rely on the examination score to be an outcome measure in determining the quality of the online learning experience. Garrison and Kanuka (2004) posited that, in addition to students' achievement measured from standardised test scores, it is essential to measure the learning process to evaluate the effects of blended learning. This measure of learning process could be based on a measure of students' learning behaviour during the online learning sessions, such as the extent of their online participation as well as the quality of work produced. To measure students' behaviour and achievement during the online learning sessions over time, a new construct, referred here as the continuous achievementrelated online performance, is included in this study. 


\section{Mediating role of continuous achievement-related online performance}

The continuous achievement-related online performance, being an important measure of students' behaviour and achievement during online learning, is closely associated with their learning effectiveness. In examining learning effectiveness, past research opined that the focus should not be solely on increasing the quantity of online participation (Swan, 2002). Rather, the quality and dynamics of students' participation in discussion forums matters in influencing learning and performance (Chong, 1998; Davies \& Graff, 2005). In predicting students' course achievements, previous studies have seldom examined students' online behaviour and achievement during online learning as a potential mediating variable. Though limited, Alstete and Beutell (2004) found that discussion board grades, based on quality and quantity of student participation, were significantly related to overall course performance in online distance learning courses. Though not a mediation study per se, the authors offered useful insights for understanding the potential mediating role of student online participation. In another study, Michinov, Brunot, Le Bohec, Juhel, and Delaval (2005) found that the relationship between students' tendency to procastinate and performance as graded by instructors in an online learning program was mediated by the level of the students' participation in discussion forums.

Given that there are limited studies that report on the extent that the CoI framework is able to explain the variance in students' actual course performance and achievement, this study is an investigation into the mediating role of continuous achievement-related online performance to provide more empirical insights for understanding the mechanisms underlying the quality of the online learning environment.

\section{Research hypotheses}

To that end, an online survey was administered to 227 students at a polytechnic institute in Singapore. Correlational analysis and structural equation modelling were used to examine the relationships between the CoI framework and students' academic achievement. By doing so, we hoped to better understand the nature of online learning that influences students' learning outcomes in a blended approach. A representation of the hypothesised model tested in this study is illustrated in Figure 1. This model can be represented by the following five research hypotheses:

- Hypothesis 1: Teaching presence would positively predict social presence and cognitive presence in an online learning environment for a blended course.

- Hypothesis 2: Social presence would take on a mediating role for teaching presence to positively predict cognitive presence in an online learning environment for a blended course.

- Hypothesis 3: Teaching presence, social presence, and cognitive presence would positively predict online course satisfaction in an online learning environment for a blended course.

- Hypothesis 4: Teaching presence, social presence, and cognitive presence would positively predict the continuous achievement-related online performance in an online learning environment for a blended course.

- Hypothesis 5: Continuous achievement-related online performance would mediate the relationship between the three elements in the CoI framework and academic achievement in an online learning environment for a blended course. 


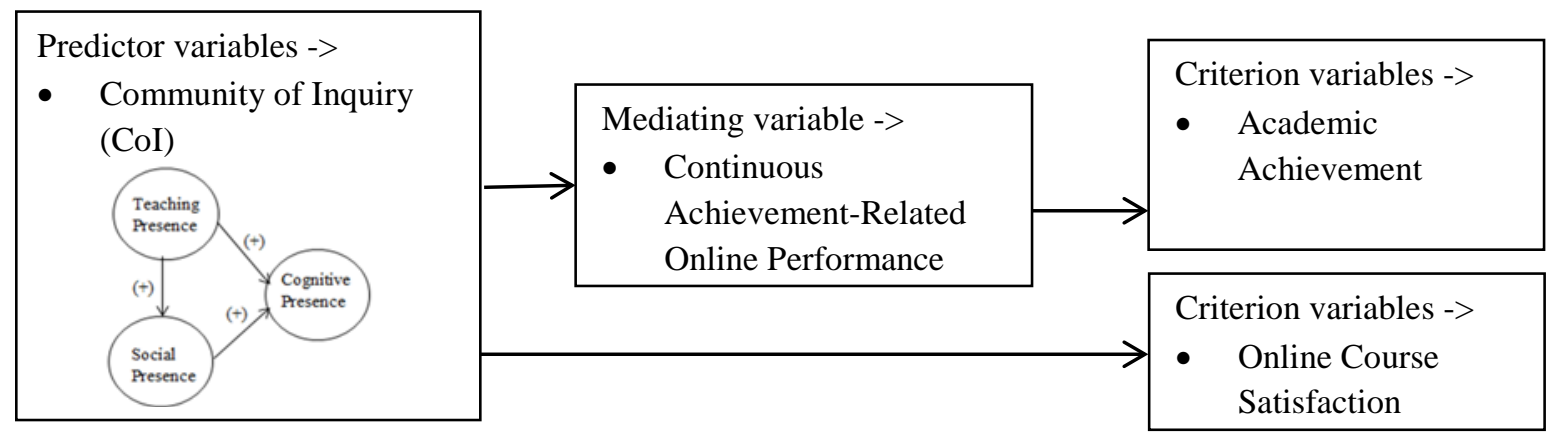

Figure 1. A hypothesised model to examine students' online learning experience and outcomes for a blended course

Note: (+) denotes hypothesised positive correlational/predictive relationship.

\section{Methodology}

\section{Participants}

Invited participants were 227 students who came from the second and third years of a 3-year post-secondary applied sciences diploma program. They were enrolled in a course on nutrition in a polytechnic institute in Singapore. A total of 164 students (77.4\% female, 22.6\% male) with an average age of $20(S D=1.6)$ years participated voluntarily in the study. Of these, 132 respondents (80.5\%) came from the second year of the study with an average age of $20(S D=1.5)$ and 32 respondents were from the third year of the program with an average age of $21(S D=1.8)$. The majority of the students $(66.5 \%)$ were between 17 and 24 years old and the rest (33.5\%) were between 18 and 26 years old.

\section{Context}

The nutrition course was an elective course offered for the second- and third-year students enrolled in the Diploma of Applied Sciences in a polytechnic institute situated in the northern part of Singapore. This course was delivered in a blended approach that integrated students' learning experiences across face-to-face and online contexts. Throughout the semester (15-week period), students accessed the online learning materials (OLMs) and performed self-directed learning via online learning to understand the content. The OLMs, consisting of a set of reading and video resources and an assignment, were released by the lecturers at the start of every 2 weeks. During the online learning component of the course, students participated in the online discussion forum as well as contacted the lecturer via online messaging to pose questions pertaining to the learning materials and assignments. On alternate weeks, students attended a 3-hour face-to-face classroom session where they engaged with the lecturer to clarify their understanding further. The face-to-face sessions provided the opportunity for lecturers to address students' learning issues and to ensure that students had acquired an accurate understanding of the concepts taught. In the classroom sessions, students were placed in small-group learning classes of not more than 25 students per class (a total of nine classes). Based on this arrangement, there were 7 OLMs, and students completed each online assignment within a 2-week timeframe. Figure 2 illustrates the processes involved in the blended learning sequence for the nutrition course. 


\begin{tabular}{|c|c|c|c|}
\hline $\begin{array}{l}\text { Step } 1 \\
\text { Lecturer releases the } \\
\text { online learning } \\
\text { materials and } \\
\text { assignment }\end{array}$ & $\begin{array}{l}\text { Step } 2 \\
\text { Students participate } \\
\text { in the discussion } \\
\text { forum and real-time } \\
\text { chat for discussion } \\
\text { and interaction }\end{array}$ & $\begin{array}{l}\text { Step } 3 \\
\text { Students attend a 3- } \\
\text { hour face-to-face } \\
\text { classroom session }\end{array}$ & $\begin{array}{l}\text { Step } 4 \\
\text { Students submit the } \\
\text { online learning } \\
\text { assignments as a } \\
\text { team }\end{array}$ \\
\hline
\end{tabular}

Figure 2. Blended learning sequence involving online learning resources and online assignments Note: The duration of steps 1 to 4 is for 2 weeks.

\section{Procedure}

Ethics approval was sought from and granted by the researchers' affiliated institution prior to data collection. The survey was administered online to all students taking the nutrition course 2 weeks before the end of the semester. An explanation of the objectives of the study and assured anonymity and confidentiality of participation were provided in the online form. Participants were instructed to focus only on their online learning experience for their responses to the survey. Participants responded to items measuring the perceived level of social presence, teaching presence, cognitive presence, self-regulation, and online course satisfaction as well as demographic items in the same online survey form. The academic achievement measure was obtained from the institution's registry database at the end of the semester.

\section{Measures}

\section{Revised CoI survey instrument}

A revised form of the CoI survey instrument (Garrison et al., 2010) was administered to assess the extent to which students experience social, teaching, and cognitive presence. Out of 34 items in the CoI survey instrument, a total of 18 items from the original instrument were selected and reviewed to enhance clarity and to fit the online learning environment of the nutrition course that was delivered in a blended approach. This included consideration of the design of the blended course and the nature of students' engagement in the online learning activities.

In terms of the course design, in any blended learning course, there are areas that are already taken care of by the instructor in the face-to-face classroom. As the original CoI survey instrument is designed with the online learning environment in mind, a certain degree of customisation was needed to cater to the course design in the blended course. For instance, in the design and organisation dimension of teaching presence, the instructor provided clear instructions on students' online participation in the course, whereas the aspect of communicating course goals and topics was conducted during the face-to-face classroom session. As such, items related to clarity of the course topics and goals were removed to better reflect the online learning environment of the blended course. The removal of certain items in this dimension was supported in other studies as well (Arbaugh, 2008; Díaz, Swan, Ice, \& Kupczynski, 2010; Shea et al., 2006). The authors observed that students tend to perceive that clarity of the course topics and goals belongs to pre-course activities in an online course. Similarly, certain items of social presence were reviewed to better fit the online context by removing two items: "I was able to form distinct impression of some course participants" and "Getting to know other course participants gave me a sense of belonging in the course" since students were able to build such affective expression during the face-to-face classroom sessions.

Some indicators were selected due to the nature of students' engagement in the online learning activities. In the online context of the nutrition course, students were frequently involved in searching for resources to answer content-related questions, discussing course issues with peers, reflecting on the content and applying the knowledge created in the course. Activities such as posing problems and brainstorming were not frequently adopted by students. Such items in the original CoI Survey were removed to better measure the extent that students perceived the presence of various layers within cognitive presence. 
Exploratory factor analyses (EFA) were conducted to evaluate the factorial structure of the 18 items from the data collected. To select and retain items in EFA, the following procedures were adopted: items that had (a) factor loadings more than .40, (b) minimal cross-loadings between factors and (c) a coherent set of scales. Using principal axis estimation with varimax rotation and Kaiser's (1960) rule of eigenvalues greater than one, 17 items across three factors were identified. These three factors were labelled social element (6 items), teaching element (5 items), and cognitive element ( 6 items). The term element was adopted instead of the original term presence to reflect how certain characteristics of each presence from the original instrument were included in the newly devised instrument. All items were scored on a 5-point Likert scale, ranging from 1 (strongly disagree) to 5 (strongly agree).

The validity of the revised CoI survey instrument was established by means of exploratory factor analysis (EFA) and confirmatory factor analysis (CFA). The data fitted the model well: Chi-square/df ratio $=1.59$, TLI $=.95$, $\mathrm{CFI}=.95$, RMSEA $=.06$. The reliability of the revised CoI survey instrument was determined by means of the Cronbach's alpha, which was .85 for teaching element,.89 for social element and .87 for cognitive element. Overall, the construct validity and reliability was deemed adequate (Nunnally, 1978).

\section{Online course satisfaction}

Learners' online course satisfaction was measured by the students' responses to four items in the last section of the survey instrument. The reliability of this measure was established by means of Cronbach's alpha, which was .88. Items of the measurement instruments used for this study are shown in Table 1.

Table 1

Items of measurement instruments

\begin{tabular}{ll}
\hline \multicolumn{1}{c}{ Variables } & Items \\
Revised CoI survey instrument & The lecturer provided clear instructions on how to participate in online \\
& learning. \\
Teaching element & The lecturer guided us towards understanding the course topics which \\
& helped me to learn in online learning. \\
& The lecturer communicated with my group frequently during online \\
& learning. \\
& The lecturer corrected misunderstandings that I have in my learning during \\
& online sessions. \\
& The lecturer provided online feedback in a timely manner. \\
& I felt that online courses are an excellent medium for social interaction. \\
& I felt comfortable communicating with my classmates through the online \\
& platforms (i.e., Edmodo, Google chat). \\
I felt that my views posted during online learning were acknowledged by \\
others. \\
My classmates fostered a sense of online community (i.e., a sense of \\
belonging, safe learning environment, shared values). \\
I felt that online discussions helped me to develop a sense of online \\
community (i.e., a sense of belonging, safe learning environment, shared \\
values). \\
The lecturer fostered a feeling of online community (i.e., a sense of \\
belonging, safe learning environment, shared values). \\
I felt that online courses are an excellent medium for social interaction. \\
I felt comfortable communicating with my classmates through the online \\
platforms (i.e., Edmodo, Google chat). \\
I felt that my views posted during online learning were acknowledged by \\
others. \\
My classmates fostered a sense of online community (i.e., a sense of \\
belonging, safe learning environment, shared values).
\end{tabular}




\begin{tabular}{ll}
\hline & I felt that online discussions helped me to develop a sense of online \\
& community (i.e., a sense of belonging, safe learning environment, shared \\
& values). \\
& The lecturer fostered a feeling of online community (i.e., a sense of \\
belonging, safe learning environment, shared values).
\end{tabular}

Continuous achievement-related online performance

The continuous achievement-related online performance measure was based on the lecturer observations which captured (a) the level of students' engagement in the online learning process, (b) the extent to which they engaged and persisted in self-directed learning, and (c) their understanding of what they had learned based on their submission of seven online group assignments. A grade was assigned to each student upon submission of each online learning assignment (i.e., seven observations). The reliability of this measure was established by means of Cronbach's alpha, which was .82. The reliability of this scale was high and acceptable.

\section{Academic achievement}

The academic achievement measure was based on written tests ranging from 45 to 90 minutes' duration conducted in three different periods within the 15-week semester. It represented the written test performance, on all three written tests, for the nutrition course to measure students' understanding of the concepts learned. Each test consisted of a combination of open-ended questions and multiple-choice questions. Each student received a grade for each test and the grades were distributed on a scale ranging from 0 to 4 with .5 increments: 0 (full fail), 0.5 (fail), 1.0 (conditional pass I), 1.5 (conditional pass II), 2.0 (acceptable), 2.5 (satisfactory), 3.0 (good), 3.5 (very good), and 4.0 (excellent). The Cronbach's alpha for this measure was .81, which indicates good reliability.

Control variables

In terms of control variables, students' characteristics were taken into consideration as some studies have found that certain demographics (i.e., gender, age, and academic level) influence students' perceptions of their sense of community in the online learning environment (Garrison et al., 2010; Richardson \& Swan, 2003; Shea \& Bidjerano, 2009). In this study, gender was found to have no significant correlation with the other main research variables. Hence, only age and academic level were selected to be controlled for further analysis in this study.

\section{Results}

\section{Descriptive statistics and zero-order correlations}

Table 2 contains the mean, standard deviation, and the interfactor correlations within and between the social element, teaching element, cognitive element, quality of online peer interaction, quality of online learning materials, continuous achievement related online performance, academic achievements, and course satisfaction based on the total sample. 
Table 2

Mean, standard deviation and interfactor correlations statistics using total sample $(N=164)$

\begin{tabular}{|c|c|c|c|c|c|c|c|c|c|c|c|}
\hline Factor/sub-scale & $\begin{array}{l}\text { No. of } \\
\text { items }\end{array}$ & $\mathrm{M}$ & SD & (1) & (2) & (3) & (4) & (5) & (6) & (7) & (8) \\
\hline Teaching element & 5 & 4.21 & .56 & - & & & & & & & \\
\hline Social element & 6 & 3.88 & .67 & $.47 * *$ & & & & & & & \\
\hline Cognitive element & 6 & 4.00 & .55 & $.53 * *$ & $.71^{* *}$ & & & & & & \\
\hline Online course satisfaction & 4 & 4.05 & .68 & $.38 * *$ & $.55^{* *}$ & $.59 * *$ & & & & & \\
\hline $\begin{array}{l}\text { Continuous achievement- } \\
\text { related online } \\
\text { performance }\end{array}$ & 7 & 3.22 & .72 & .14 & .06 & $.24 * *$ & .09 & & & & \\
\hline Academic achievement & 3 & 2.24 & 1.05 & .10 & -.03 & $.20 *$ & .07 & $.56 * *$ & - & & \\
\hline Age & 1 & 1.34 & .47 & -.13 & -.19 & $-.25 * *$ & $-.22 * *$ & -.07 & $-.27 * *$ & - & \\
\hline Academic Levels & 1 & 1.20 & .40 & .06 & -.20 & -.04 & -.04 & $.26 * *$ & $.409 * *$ & .14 & - \\
\hline
\end{tabular}

Note. SD represents standard deviation.

**. Correlation is significant at the 0.01 level (2-tailed).

* Correlation is significant at the 0.05 level (2-tailed).

Results reveal that online course satisfaction has a significant positive relationship with the teaching element $(r$ $=.38, p<.01)$, social element $(r=.55, p<.01)$, and cognitive element $(r=.59, p<.01)$. A significant positive relationship was found between the cognitive element and continuous achievement-related online performance $(r=.24, p<.01)$. Academic achievement was positively related to the continuous achievement-related online performance $(r=.56, p<.01)$ as well as the cognitive element $(r=.20, p=.01)$. Age was negatively correlated with cognitive element $(r=-.25, p<.01)$, continuous achievement-related online performance $(r=-.22, p<.01)$, and academic achievement $(r=-.27, p<.01)$. Academic level was positively correlated with continuous achievement-related online performance $(r=.26, p<.01)$, and academic achievement $(r=.41, p<.01)$.

\section{Analysis of the structural model}

The full structural model of the hypothesised relationships was statistically tested using AMOS 18.0. Path analysis using maximum likelihood estimation was performed to examine the direct and indirect (i.e., mediating) relations among social element, teaching element, cognitive element, quality of online peer interaction, quality of online learning materials, continuous achievement-related online performance, academic achievement, and course satisfaction. To assess the overall goodness of fit, chi-square, accompanied by degrees of freedom and other fit indices (namely CLI, TLI, NFI and RMSEA), were considered.

The results of the analysis reveal that the data fit the hypothesized model (Chi-square/df ratio $=1.55$, CFI $=.901$, $\mathrm{TLI}=.892$, NFI $=.766$, and RMSEA $=.058$ ). All factor loadings were statistically significant at less than $1 \%$ level. The results of the model, which included a measure of social presence as a partial mediator between teaching presence and cognitive presence, continuous achievement-related online performance, academic achievement and course satisfaction, are depicted in Figure 3. 


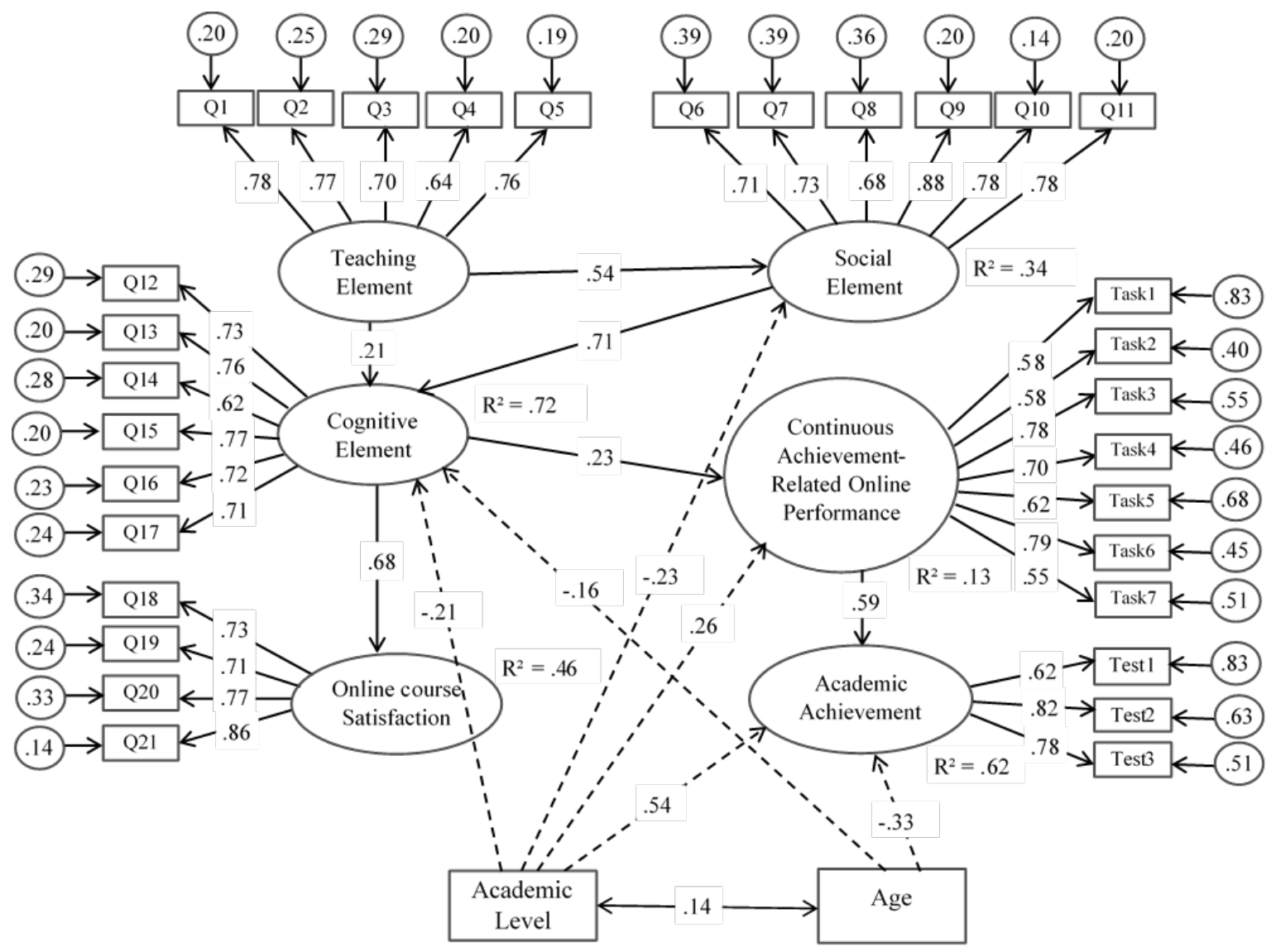

Figure 3. The path model depicting relationships among teaching element, social element, cognitive element, continuous achievement-related online performance, academic achievement and course satisfaction Note. Numbers above the arrows represent standard regression weights. All standard regression weights are statistically significant at the $1 \%$ level.

The relationships among variables in the hypothesised model were as follows: Firstly, in terms of relationships among the three CoI elements, results indicate that teaching element positively and significantly predicted both social element $(\beta=.54, p<.01)$, and cognitive element $(\beta=.21, p<.01)$. In addition, social element functions as a partial mediator and was the strongest predictor for cognitive element $(\beta=.71, p<.01)$. Thus, the first hypothesis that teaching presence would positively predict social presence and cognitive presence and the second hypothesis that social presence would take on a mediating role for teaching presence to positively predict cognitive presence in an online learning environment for a nutrition course that was conducted in a blended approach to learning were supported. Secondly, cognitive element has a significant and direct effect on continuous achievement-related online performance $(\beta=.23, p<.01)$. In addition, continuous achievementrelated online performance was indirectly predicted by social element $(\beta=.17, p<.01)$ and teaching element $(\beta=.14, p<.01)$ via the cognitive element. Thirdly, in terms of the relationships among the predictor variables and online course satisfaction, results indicate that the cognitive element has a significant and direct effect on students' online satisfaction level $(\beta=.68, p<.01)$. In addition, online satisfaction was indirectly predicted by the social element $(\beta=.49, p<.01)$ and the teaching element $(\beta=.41, p<.01)$ via the cognitive element.

Finally, the mediating role of continuous achievement-related online performance in the relationships among teaching elements, social elements, cognitive elements, and academic achievement were examined. From mediation analysis, results indicate that the social element $(\beta=.10, p<.01)$ and the cognitive element $(\beta=.14$, 
$p<.01)$ indirectly predicted academic achievements via continuous achievement-related online performance. Thus, hypotheses 3, 4 and 5 were partially supported.

The direct, indirect and total effects among the research variables measured are presented in Table 3.

Table 3

Standardised direct, indirect and total effects

\begin{tabular}{|c|c|c|c|c|}
\hline Predictor & Criterion variable & $\begin{array}{l}\text { Direct } \\
\text { effect }\end{array}$ & $\begin{array}{l}\text { Indirect } \\
\text { effect }\end{array}$ & $\begin{array}{l}\text { Total } \\
\text { effect }\end{array}$ \\
\hline \multirow[t]{5}{*}{ Teaching element } & Social element & .536 & - & .536 \\
\hline & Cognitive element & .214 & .382 & .596 \\
\hline & $\begin{array}{l}\text { Continuous achievement-related online } \\
\text { performance }\end{array}$ & - & .138 & .138 \\
\hline & Academic achievement & - & .082 & .082 \\
\hline & Online course satisfaction & - & .405 & .405 \\
\hline \multirow[t]{4}{*}{ Social element } & Cognitive element & .714 & - & .714 \\
\hline & $\begin{array}{l}\text { Continuous achievement-related online } \\
\text { performance }\end{array}$ & - & .166 & .166 \\
\hline & Academic achievement & - & .098 & .098 \\
\hline & Online course satisfaction & - & .485 & .485 \\
\hline \multirow[t]{3}{*}{ Cognitive element } & $\begin{array}{l}\text { Continuous achievement-related online } \\
\text { performance }\end{array}$ & .232 & - & .232 \\
\hline & Academic achievement & - & .138 & .138 \\
\hline & Online course satisfaction & .680 & - & .680 \\
\hline $\begin{array}{l}\text { Continuous } \\
\text { achievement-related } \\
\text { online performance }\end{array}$ & Academic achievement & .593 & - & .593 \\
\hline
\end{tabular}

\section{Discussion}

The purpose of this study was to explore students' online learning experience in a blended course through elements within the CoI framework. The study also examined the structural relationships among the social element, teaching element, cognitive element, online course satisfaction, continuous achievement-related online performance, and academic achievement.

First, based on the mean scores reported, a relatively high sense of all three elements was observed with teaching element receiving the highest ratings $(M=4.21)$, followed by the cognitive element $(M=4.00)$, and the social element $(M=3.88)$. The students also agreed that they were satisfied with the online learning approach $(M=$ 4.05). This indicates that the CoI components of teaching, social, and cognitive elements were distinctively present in the online learning environment designed for the nutrition course.

Second, the structural relationships among social element, teaching element, and cognitive element were examined. Our results support claims made in earlier literature regarding the implications of the CoI framework on the design and instructions for online learning. The strong association between teaching presence and cognitive presence reflects Garrison and Cleveland-Innes' (2005) illustration of teaching presence being crucial in providing structure (i.e., design) and leadership (i.e., facilitation and direction) to guide deep and meaningful learning in the online environment. The social element function as the partial mediator to predict cognitive element supports the claim put forth by Rourke, Anderson, Garrison, and Archer (2007) that learners with a high sense of social presence will initiate and sustain a critical thinking process with a community of learners to achieve the cognitive objectives. Overall, about $72 \%$ of the variance in the cognitive element was explained in this model. This result is comparable to what was reported by Shea and Bidjerano (2009), whose model was able to explain $63 \%$ of the variance in cognitive presence. 
Third, this study highlighted the positive relationships between the CoI framework and online course satisfaction. The hypothesised model could uniquely explain for $46 \%$ of the variance in online course satisfaction, higher than what was reported in earlier studies (i.e., Arbaugh, 2008; Enightoola et al., 2014). Our results indicate a strong positive correlations among teaching, social, and cognitive elements with online course satisfaction. This indicates that students who perceived higher levels of teaching element, social element, and cognitive element also perceived a higher level of online course satisfaction. Further exploration into the direct and indirect relationships among these variables partially supports what has been reported in earlier studies. Consistent with previous research (Akyol \& Garrison, 2011; Enightoola et al., 2014; Joo et al., 2011), cognitive element was significantly related to online course satisfaction. While the result of this study indicates that teaching element and the social element influenced student satisfaction, their impact was not direct, but was mediated by the cognitive element. This result might be caused by differences in the research context. For example, the present study surveyed post-secondary students taking a nutrition course using a blended approach in a polytechnic institute. In a blended approach, the sense of social presence in an online learning environment might not be strong enough to influence a significant effect on satisfaction as students and lecturers might still fall back on the face-to-face classroom opportunities for communication purposes. Although the teaching element had the highest mean score when compared to cognitive and social elements, no significant correlation was found with satisfaction. The instructor ability to facilitate frequent and effective interaction with and among students is found to be important in establishing a sense of connectedness and learning, as well as course satisfaction (Shea et al., 2005). This might suggest that further efforts are required from the lecturer to improve the level of social element in the online learning environment.

Fourth, only the cognitive element was found to have a direct and positive relationship with the continuous achievement-related online performance measure. Similar to the findings discussed above, social element and teaching element indirectly predicted continuous achievement-related online performance through the cognitive element. This has been not typical of previous studies where teaching presence and cognitive presence were reported to be the primary drivers of students' perceived learning (Arbaugh, 2008; Aykol \& Garrison, 2011). The lack of a direct relationship with teaching presence may have two possible explanations. The first explanation is that students might think that they learn more when they perceive sufficient levels of teaching and cognitive presence. However, when it comes to actual products of the knowledge created from online learning, the extent that students experienced sufficient levels of cognitive presence matters more. This is despite students experiencing a higher sense of teaching presence in the course. The second explanation is that the tasks activities and knowledge created from online learning in the nutrition course relate closely with the various dimensions in cognitive presence. Shea et al. (2009) observed that threaded discussion often only triggers the initial stages in the learning cycle. But the advanced stages in the learning cycle of cognitive presence (i.e., integration and resolution) and deeper learning were found to be initiated by other course learning activities. For example, Kanuka, Rourke, \& Laflamme (2007) found that the level of cognitive presence was the highest during WebQuests and debate activities. This suggests that the instructional methods and technologies adopted for online learning need to promote reflective thinking and critical discourse in order to influence the quality of students' learning.

Fifth, this study highlighted the important dual roles of continuous achievement-related online performance, which provided a measurement of online performance over time, can possibly be used with the CoI framework as a predictor as well as a mediator to predict academic achievement. Using continuous achievement-related online performance, the model was able to explain $62 \%$ of the variance in academic achievement. This $\mathrm{R}^{2}$ value was higher than the variances reported in the earlier studies by Arbaugh (2008) and Enightoola et al. (2014), where $54 \%$ and $29 \%$ of the variance in learning were explained respectively.

Results of the present study suggest that having a high level of cognitive element is necessary in online learning for students to achieve a high sense of satisfaction and to do well in online assignments in a blended course. It is also clear from the results that students reporting lower levels of teaching and social element are likely to report lower levels of cognitive element, with social element having a higher correlation. This finding echoes what has been reported in the Shea et al. (2009) study that while students reporting low social presence are far more likely to report low cognitive presence, teaching presence might have played a moderating role. The authors argued that in a blended learning environment, where students had some opportunity for face-to-face 
interaction with their instructors and peers, having good teaching presence is imperative to mitigate the absence of dynamic and real-time interactions during online learning. Based on Garrison and Cleveland-Innes' (2005) recommendations, it is important for teachers and instructional designers to consider how they can facilitate productive discourse and direct instruction to involve students in constructing and confirming meaning through sustained reflection and discourse when designing an online learning environment. For instance, when providing direct instruction, instructors should provide clear instructions on how students should participate in online activities. Particularly in a blended course, the online activities should be clear on how activities are connected to face-to-face learning. This is to ensure that the face-to-face and online components are well integrated. To facilitate productive discourse, it is important to provide appropriate guidance about the course topics and to be attentive to students' learning needs. This includes facilitating conditions where active participation from students is encouraged, creating a climate in which all students feel included, monitoring students' progress, and addressing learning gaps (Shea at el., 2006).

\section{Limitations and suggestions for future research}

It is important to note several limitations of this study. Firstly, as this study was designed as a cross-sectional study, its ability to establish causal relationships among variables is limited. Future research could test this model longitudinally or conduct experimental studies to clarify the causal relationships among the variables.

Secondly, the current study mainly relied on student self-reports of phenomena experienced in the online learning environment to inform the level of teaching, social and cognitive presence. Although students' actual learning achievements (e.g., online assignments submitted) were included in the analysis, there are limitations associated with survey-based research as the analysis tends to focus on exploring relationships between a specific set of variables. Moreover, a caveat to measuring behaviours and learning outcomes with perception and test scores is that it might not be a representation of students' actual online engagement level. It would be greatly preferable in future studies to obtain various data sources that provide direct and rich information such as observing online interactions and interviewing students to gain insights into their online learning behaviour. Additionally, the revised CoI questionnaire did not include all the items from the original CoI instrument; therefore, specific dimensions associated with each of the presences in the CoI framework could not be distinguished to further analyse possible iterations affecting the relationship. Future research could consider using all the items in the original CoI instrument.

Thirdly, a challenge with this study is defining the measure that relates the success in academic achievement with students' online learning experiences in a blended course. This study posited that students' online learning behaviour and achievements as observed by the lecturer, referred here as continuous achievement-related online performance, is to be used as a mediator for the CoI framework to predict students' overall academic achievement in the course. Further research could test and validate this relationship to support the use of this mediator variable.

Finally, this study was conducted in a polytechnic institutional context with students taking the nutrition course, which may not be representative enough among the various courses offered. Therefore, the generalisability of the results reported here to a larger population is limited. Future research could examine if a different learning context, such as a different type of course or variation in students' exposure to online learning in a blended learning design, would reveal similar findings using the hypothesised model.

\section{Conclusion}

Interactions among the components of CoI framework with students' sense of satisfaction and academic achievement depict a complex and dynamic process which deserves greater empirical attention.

The first implication is that the instructors should pay close attention to the different emphases of instructional strategies when engaging learners in online learning. Given that this is a blended course, the facilitation skills deployed should take into consideration what is important for the online learning environment and be careful 
to explore possibilities to connect them seamlessly into the face-to-face setting or incorporate other facilitation skills that could be extended to the face-to-face setting.

The second implication for designers would be to design authentic learning tasks that provide learners with the opportunity to engage in discussions with their peers and apply the knowledge created in the course. It also highlights the importance for designers to consider carefully the affordances and limitations of the chosen technological platform and the learning outcome to support learners' learning as they engage in more sophisticated knowledge construction.

The third implication for the instructors would be to motivate learners to develop their learning trajectory in the online environment by teaching them how to ask questions, seek clarification, challenge assumptions and reflect on their learning. It also highlights the importance of having a continuous measurement of learners' online learning behaviour and achievement in predicting academic achievement. This can be done by demonstrating the dual roles of the continuous achievement-related online performance measure as a predictor and a mediator variable. Further studies could look into investigating the nature of learners' online interactions and engagement with the online learning tasks that will support quality learning.

\section{References}

Ackerman, R., \& Goldsmith, M. (2011). Metacognitive regulation of text learning: On screen versus on paper. Journal of Experimental Psychology: Applied, 17(1), 18-32. http://dx.doi.org/10.1037/a0022086

Ackerman, R., \& Lauterman, T. (2012). Taking reading comprehension exams on screen or on paper? A metacognitive analysis of learning texts under time pressure. Computers in Human Behavior, 28(5), 18161828. http://dx.doi.org/10.1016/j.chb.2012.04.023

Akyol, Z., \& Garrison, D. R. (2011). Understanding cognitive presence in an online and blended community of inquiry: Assessing outcomes and processes for deep approaches to learning. British Journal of Educational Technology, 42(2), 233-250. http://dx.doi.org/10.1111/j.1467-8535.2009.01029.x

Alstete, J., \& Beutell, N. (2004). Performance indicators in online distance learning courses: A study of management education. Quality Assurance in Education, 12(1), 6-14. http://dx.doi.org/10.1108/09684880410517397

Anderson, T., Liam, R., Garrison, D. R., \& Archer, W. (2001). Assessing teacher presence in a computer conferencing context. Journal of Asynchronous Learning Networks, 5(2), 1-17. Retrieved from http://auspace.athabascau.ca/handle/2149/725

Arbaugh, J. B. (2008). Does the community of inquiry framework predict outcomes in online MBA courses? The International Review of Research in Open and Distance Learning, 9(2), 1-21. Retrieved from http://www.irrodl.org/index.php/irrodl/article/view/490/1045

Arbaugh, J. B., Cleveland-Innes, M., Diaz, S. R., Garrison, D. R., Ice, P., Richardson, J. C., \& Swan, K. P. (2008). Developing a community of inquiry instrument: Testing a measure of the community of inquiry framework using a multi-institutional sample. The Internet and Higher Education, 11(3), 133-136. http://dx.doi.org/10.1016/j.iheduc.2008.06.003

Arbaugh, J. B., \& Hwang, A. (2006). Does "teaching presence" exist in online MBA courses? The Internet and Higher Education, 9(1), 9-21. http://dx.doi.org/10.1016/j.iheduc.2005.12.001

Association of American Colleges and Universities. (2008). Our students' best work: A framework for accountability worthy of our mission (2nd ed.). Washington, DC: Association of American Colleges and Universities.

Babb, S., Stewart, C., \& Johnson, R. (2010). Constructing communication in blended learning environments: Students' perceptions of good practice in hybrid courses. Journal of Online Learning and Teaching, 6(4), 735-753. Retrieved from http://jolt.merlot.org/vol6no4/babb_1210.htm

Burge, E. J., \& Roberts, J. M. (1993). Classrooms with a difference: A practical guide to the use of conferencing technologies. Ontario: University of Toronto Press.

Cheung, W. S., \& Hew, K. F. (2011). Design and evaluation of two blended learning approaches: Lessons learned. Australasian Journal of Educational Technology, 27(8), 1319-1337. http://dx.doi.org/10.14742/ajet.896 
Chong, S. M. (1998). Models of asynchronous computer conferencing for collaborative learning in large college classes. In C. J. Bonk \& K. S. King (Eds), Electronic collaborators: Learner-centered technologies for literacy, apprenticeship, and discourse (pp. 157-182). Mahwah, NJ: Lawrence Erlbaum Associates.

Choppin, B. H. (1990). Evaluation, assessment, and measurement. In H. J. Walberg \& G. D. Haertel (Eds.), The international encyclopedia of educational evaluation (pp. 7-8). New York, NY: Pergamon.

Chung, J., \& Davis, I. K. (1995). An instructional theory for learner control: Revisited. In M. R. Simonson (Ed.), Proceedings of the 1995 Annual National Convention of the Association for Educational Communications and Technology (pp. 72-86). Anaheim, CA: AACE.

Davies, J., \& Graff, M. G. (2005). Performance in e-learning: Online participation and student grades. British Journal of Educational Technology, 36(4), 657-663. http://dx.doi.org/10.1111/j.1467-8535.2005.00542.x

Dewey, J. (1933). How we think: A restatement of the relation of reflective thinking to the educative process. Lexington, MA: Heath.

Díaz, S. R., Swan, K., Ice, P., \& Kupczynski, L. (2010). Student ratings of the importance of survey items, multiplicative factor analysis, and the validity of the community of inquiry survey. The Internet and Higher Education, 13(1), 22-30. http://dx.doi.org/10.1016/j.iheduc.2009.11.004

Dukes, L. L., Waring, S. M., \& Koorland, M. A. (2006). The blended course delivery method: The not-sodistant education. Journal of Computing in Teacher Education, 22(4), 153-158. Retrieved from http://www.learntechlib.org/p/55265

Dunlap, J. C., Sobel, D., \& Sands, D. I. (2007). Designing for deep and meaningful student-to-content interactions. Tech Trends: Linking Research \& Practice to Improve Learning, 51(4), 20-31. http://dx.doi.org/10.1007/s11528-007-0052-6

Enightoola, K., Fraser, S., \& Brunton, T. (2014). Exploring the community of inquiry model: Students' attitudes towards e-learning. The Caribbean Teaching Scholar, 4(2), 81-98. Retrieved from http://libraries.sta.uwi.edu/journals/ojs/index.php/cts/article/view/501

Garrison, D. R., Anderson, T., \& Archer, W. (1999). Critical inquiry in a text-based environment: Computer conferencing in higher education. The Internet and Higher Education, 2(2), 87-105. http://dx.doi.org/10.1016/S1096-7516(00)00016-6

Garrison, D. R., Anderson, T., \& Archer, W. (2003). A theory of critical inquiry in online distance education. In M. G. Moore \& W. G. Anderson (Eds.), Handbook of distance education (pp. 113-127). London: Laurence Erlbaum.

Garrison, D. R., \& Arbaugh, J. B. (2007). Researching the community of inquiry framework: Review, issues, and future directions. The Internet and Higher Education, 10(3), 157-172. http://dx.doi.org/10.1016/j.iheduc.2007.04.001

Garrison, D. R., \& Cleveland-Innes, M. (2005). Facilitating cognitive presence in online learning: Interaction is not enough. The American Journal of Distance Education, 19(3), 133-148. http://dx.doi.org/10.1207/s15389286ajde1903_2

Garrison, D. R., Cleveland-Innes, M., \& Fung, T. S. (2010). Exploring causal relationships among teaching, cognitive and social presence: Student perceptions of the community of inquiry framework. The Internet and Higher Education, 13(1), 31-36. http://dx.doi.org/10.1016/j.iheduc.2009.10.002

Garrison, D. R., \& Kanuka, H. (2004). Blended learning: Uncovering its transformative potential in higher education. The Internet and Higher Education, 7(2), 95-105. http://dx.doi.org/10.1016/j.iheduc.2004.02.001

Gaytan, J., \& McEwen, B. C. (2007). Effective online instructional and assessment strategies. The American Journal of Distance Education, 21(3), 117-132. http://dx.doi.org/10.1080/08923640701341653

Glaser, R., \& Nitko, AJ. (1971). Measurement in learning and instruction. In R. L. Thorndike (Ed.), Educational measurement (pp. 625-670). Washington, DC: American Council on Education.

Gunawardena, C. N. (1995). Social presence theory and implications for interaction and collaborative learning in computer conferences. International Journal of Educational Telecommunications, 1(2), 147-166. Retrieved from http://www.learntechlib.org/d/15156

Gunawardena, C. N., \& Zittle, F. J. (1997). Social presence as a predictor of satisfaction within a computermediated conferencing environment. American Journal of Distance Education, 11(3), 8-26. http://dx.doi.org/10.1080/08923649709526970 
Hara, N., \& Kling, R. (2000). Students' distress with a web-based distance education course: An ethnographic study of participants' experiences. Information, Communication and Society, 3, 557-579. http://dx.doi.org/10.1080/13691180010002297

Heinich, R., Molenda, M., Russel, J. D., \& Smaldino, S. E. (2002). Instructional media and technologies for learning. Upper Saddle River, NJ: Merrill Prentice Hall.

Hostetter, C., \& Busch, M. (2006). Measuring up online: The relationship between social presence and student learning satisfaction. Journal of Scholarship of Teaching and Learning, 6(2), 1-12. Retrieved from http://josotl.indiana.edu/article/view/1670/1668

Jonassen, D., Davidson, M., Collins, M., Campbell, J., \& Haag, B. B. (1995). Constructivism and computer mediated communication in distance education. American Journal of Distance Education, 9(2), 7-26. http://dx.doi.org/10.1080/08923649509526885

Joo, Y. J., Lim, K. Y., \& Kim, E. K. (2011). Online university students' satisfaction and persistence: Examining perceived level of presence, usefulness and ease of use as predictors in a structural model. Computers \& Education, 57(2), 1654-1664. http://dx.doi.org/10.1016/j.compedu.2011.02.008

Kaiser, H. F. (1960). The application of electronic computers to factor analysis. Educational and Psychological Measurement, 20, 141-151. http://dx.doi.org/10.1177/001316446002000116

Kanuka, H., Rourke, L., \& Laflamme, E. (2007). The influence of instructional methods on the quality of online discussion. British Journal of Educational Technology, 38(2), 260-271. http://dx.doi.org/10.1111/j.1467-8535.2006.00620.x

Ke, F. (2010). Examining online teaching, cognitive, and social presence for adult students. Computers \& Education, 55(2), 808-820. http://dx.doi.org/10.1016/j.compedu.2010.03.013

Kim, J., Kwon, Y., \& Cho, D. (2011). Investigating factors that influence social presence and learning outcomes in distance higher education. Computers \& Education, 57(2), 1512-1520. http://dx.doi.org/10.1016/j.compedu.2011.02.005

Koriat, A., \& Bjork, R. A. (2005). Illusions of competence in monitoring one’s knowledge during study. Journal of Experimental Psychology: Learning, Memory, and Cognition, 31(2), 187-194. http://dx.doi.org/10.1037/0278-7393.31.2.187

Kruger, J., \& Dunning, D. (1999). Unskilled and unaware of it: how difficulties in recognizing one's own incompetence lead to inflated self-assessments. Journal of Personality and Social Psychology, 77(6), 1121-1134. http://dx.doi.org/10.1037/0022-3514.77.6.1121

Martyn, M. (2003). The hybrid online model: Good practice. Educause Quarterly, 26(1), 18-23. Retrieved from http://eric.ed.gov/?id=EJ666404

Means, B., Toyama, Y., Murphy, R., Bakia, M., \& Jones, K. (2009). Evaluation of evidence-based practices in online learning: A meta-analysis and review of online learning studies. Washington, DC: US Department of Education, Office of Planning, Evaluation, and Policy Development.

Michinov, N., Brunot, S., Le Bohec, O., Juhel, J., \& Delaval, M. (2011). Procrastination, participation, and performance in online learning environments. Computers \& Education, 56(1), 243-252. http://dx.doi.org/10.1016/j.compedu.2010.07.025

Nunnally, J. (1978). Psychometric theory. New York, NY: McGraw-Hill.

Picciano, A. G. (2002). Beyond student perceptions: Issues of interaction, presence, and performance in an online course. Journal of Asynchronous Learning Networks, 6(1), 21-40. Retrieved from http://sloanconsortium.org/sites/default/files/v6n1_picciano_1.pdf

Quek, C. L. (2007). What is happening in my first year pre-service teachers' online learning environment? In ICT: Providing choices for learners and learning. Proceedings Ascilite Singapore 2007 (pp. 880-883). Retrieved from http://www.ascilite.org.au/conferences/singapore07/procs/quek.pdf

Reeves, T. C. (2000). Alternative assessment approaches for online learning environments in higher education. Journal of Educational Computing Research, 23(1), 101-111. http://dx.doi.org/10.2190/GYMQ-78FA-WMTX-J06C

Rhodes, M. G., \& Castel, A. D. (2008). Memory predictions are influenced by perceptual information: Evidence for metacognitive illusions. Journal of Experimental Psychology: General, 137(4), 615. http://dx.doi.org/10.1037/a0013684 
Richardson, J., \& Swan, K. (2003). Examining social presence in online courses in relation to students' perceived learning and satisfaction, Journal of Asynchronous Learning Networks, 7(1), 68-88. Retrieved from http://hdl.handle.net/2142/18713

Rourke, L., Anderson, T., Garrison, D. R., \& Archer, W. (2007). Assessing social presence in asynchronous text-based computer conferencing. International Journal of E-Learning \& Distance Education, 14(2), 50 71. Retrieved from http://www.ijede.ca/index.php/jde/article/view/153/341

Rovai, A. P. (2002). Sense of community, perceived cognitive learning, and persistence in asynchronous learning networks. The Internet and Higher Education, 5(4), 319-332. http://dx.doi.org/10.1016/S10967516(02)00130-6

Rovai, A. P., \& Jordan, H. (2004). Blended learning and sense of community: A comparative analysis with traditional and fully online graduate courses. The International Review of Research in Open and Distance Learning, 5(2), 1-17. Retrieved from http://www.irrodl.org/index.php/irrodl/article/view/192/274

Sergiovanni, T. J. (1994). Building community in schools. San Francisco, CA: Jossey-Bass.

Shea, P., \& Bidjerano, T. (2009). Community of inquiry as a theoretical framework to foster "epistemic engagement" and "cognitive presence" in online education. Computers \& Education, 52(3), 543-553. http://dx.doi.org/10.1016/j.compedu.2008.10.007

Shea, P., Fredericksen, E. E., Pickett, A., \& Pelz, W. (2003). A preliminary investigation of "teaching presence" in the SUNY learning network. Elements of Quality Online Education: Practice and Direction, 4, 279-312. Retrieved from http://cpd.suny.edu/files/teachingpresence.pdf

Shea, P., Li, C., \& Pickett, A. (2006). A study of teaching presence and student sense of learning community in fully online and web-enhanced college courses. The Internet and Higher Education, 9(3), 175-190. http://dx.doi.org/10.1016/j.iheduc.2006.06.005

Shea, P., Li, C., Swan, K., \& Pickett, A. (2005). Developing learning community in online asynchronous college courses: The role of teaching presence. Journal of Asynchronous Learning Networks, 9(4), 59-82. Retrieved from http://onlinelearningconsortium.org/sites/default/files/v9n4_shea_2.pdf

So, H.-J., \& Brush, T. A. (2008). Student perceptions of collaborative learning, social presence and satisfaction in a blended learning environment: Relationships and critical factors. Computers \& Education, 51(1), 318-336. http://dx.doi.org/10.1016/j.compedu.2007.05.009

So, H.-J., \& Kim, B. (2005). Instructional methods for computer supported collaborative learning (CSCL): A review of case studies. In T. Chan, D. Suthers, \& T. Koschmann (Eds.), Proceedings of the 2005 conference on Computer Supported Collaborative Learning (pp. 607-626). Mahwah, NJ: Lawrence Erlbaum Associates Inc.

Swan, K. (2002). Building learning communities in online courses: The importance of interaction. Education, Communication and Information, 2, 23-49. http://dx.doi.org/10.1080/1463631022000005016

Turoff, M. (1995). Designing a virtual classroom. International Journal of Educational Telecommunications, 1(2), 245-262. Retrieved from http://www.learntechlib.org/p/15162

Wanstreet, C. E. (2006). Interaction in online learning environments. Quarterly Review of Distance Education, 7(4), 399-411. Retrieved from http://www.learntechlib.org/p/106711

Corresponding author: Jeanette Lyn Fung Choy, jnchoy@gmail.com

Australasian Journal of Educational Technology (c) 2016.

Please cite as: Choy, J. L. F., Quek, C. L., (2016). Modelling relationships between students' academic achievement and community of inquiry in an online learning environment for a blended course. Australasian Journal of Educational Technology, 32(4), 106-124. http://dx.doi.org/10.14742/ajet.2500 